\title{
Development of genomic simple sequence repeat markers in opium poppy by next-generation sequencing
}

\author{
Ibrahim Celik • Visam Gultekin · Jens Allmer • \\ Sami Doganlar • Anne Frary
}

Received: 10 July 2013/Accepted: 23 January 2014/Published online: 6 February 2014

(C) Springer Science+Business Media Dordrecht 2014

\begin{abstract}
Opium poppy (Papaver somniferum L.) is an important pharmaceutical crop with very few genetic marker resources. To expand these resources, we sequenced genomic DNA using pyrosequencing technology and examined the DNA sequences for simple sequence repeats (SSRs). A total of $1,244,412$ sequence reads were obtained covering $474 \mathrm{Mb}$. Approximately half of the reads (52\%) were assembled into 166,724 contigs representing $105 \mathrm{Mb}$ of the opium poppy genome. A total of 23,283 nonredundant SSRs were identified in 18,944 contigs (11.3\% of total contigs). Trinucleotide and tetranucleotide repeats were the most abundant SSR repeats, accounting for 49.0 and $27.9 \%$ of all SSRs, respectively. The AAG/TTC repeat was the most abundant trinucleotide repeat, representing $19.7 \%$ of trinucleotide repeats. Other SSR repeat types were AT-rich. A total of 23,126 primer pairs (98.7\% of total SSRs) were designed to amplify SSRs. Fifty-three genomic SSR markers were tested in 37 opium poppy accessions and seven Papaver species for determination of polymorphism and transferability. Intraspecific
\end{abstract}

Electronic supplementary material The online version of this article (doi:10.1007/s11032-014-0036-0) contains supplementary material, which is available to authorized users.

I. Celik · V. Gultekin · J. Allmer · S. Doganlar .

A. Frary $(\bowtie)$

Department of Molecular Biology and Genetics, Izmir Institute of Technology, Urla, Izmir 35430, Turkey

e-mail: annefrary@iyte.edu.tr polymorphism information content (PIC) values of the genomic SSR markers were intermediate, with an average 0.17 , while the interspecific average PIC value was slightly higher, 0.19 . All markers showed at least $88 \%$ transferability among related species. This study increases sequence coverage of the opium poppy genome by sevenfold and the number of opium poppyspecific SSR markers by sixfold. This is the first report of the development of genomic SSR markers in opium poppy, and the genomic SSR markers developed in this study will be useful in diversity, identification, mapping and breeding studies in opium poppy.

Keywords GS-FLX pyrosequencing technology · Genetic diversity · Genomic SSRs . Microsatellites · Papaver somniferum L.

\section{Introduction}

Opium poppy (Papaver somniferum L.) produces several pharmaceutically important alkaloids and is an economically important member of the family Papaveraceae (Acharya and Sharma 2009). Benzylisoquinoline alkaloids are extracted from opium poppy and have extensive medicinal properties, including analgesic and narcotic (morphine), antitumor (noscapine), antitussive (codeine) and muscle relaxant (papaverine) effects (Facchini and De Luca 2008; Ziegler et al. 2009; Winzer et al. 2012). In addition, poppy seeds and their oil are edible (Schulz et al. 
2004). Although Turkey currently ranks first in the world in terms of surface area of cultivated opium poppy fields with 49,000 hectares (48 \% of the world total), the country ranks second in total world morphine production, with 150 tons (18\% of the world total), after Australia (23\%), due to the low morphine content of Turkish poppy (Turkish Soil Product Office 2009). An important contributing factor to the use of low-morphine cultivars is a lack of poppy-specific molecular tools for characterization of poppy germplasm and more efficient breeding (Gumuscu and Arslan 2008).

To date, molecular characterization of opium poppy has mainly involved the use of non-specific markers, such as amplified fragment length polymorphism (AFLP) (Saunders et al. 2001; Dittbrenner et al. 2008), random amplified polymorphic DNA (RAPD) and inter-simple sequence repeat (Acharya and Sharma 2009; Parmaksiz and Ozcan 2011) markers. The most comprehensive analysis of genetic diversity of opium poppy was done by Dittbrenner et al. (2008), who analyzed the genetic diversity of 300 accessions from the opium poppy world collection using AFLP markers. These authors also quantified major alkaloids (morphine, codeine, thebaine, papaverine and noscapine) in the accessions by high performance liquid chromatography. Straka and Nothnagel (2002) constructed the only genetic linkage map currently available for opium poppy using 77 AFLP and 48 RAPD markers. Thus, it is clear that opium poppyspecific markers would be a valuable contribution to diversity and mapping studies.

Simple sequence repeat (SSR) or microsatellite markers are iterations of one to six nucleotide motifs and are dispersed throughout the genome (Varshney et al. 2005; Jones et al. 2009). Although genic SSR markers are gene targeted and more conserved than genomic SSR markers, they are reported to have lower copy number and lower polymorphism information content (PIC) than genomic SSR markers (Li et al. 2002; Ellis and Burke 2007). Opium poppy-specific markers have recently been developed using the publicly available expressed sequence tag (EST) database [National Center for Biotechnology Information (NCBI), Bethesda, MD] to identify and design SSR primers (Lee et al. 2011; Selale et al. 2013). Lee et al. (2011) developed 22 opium poppy-specific genic SSR markers but tested only six of these for molecular characterization of opium poppy. Selale et al. (2013) tested 67 EST-SSR primer pairs on Turkish opium poppy accessions, landraces and cultivars. In these two latter studies, the markers were validated for use in forensic identification of opium poppy (Lee et al. 2011) and genetic diversity analysis (Selale et al. 2013). In both cases, opium poppy-specific genic SSR markers revealed low genetic diversity. Given the low polymorphism and limited number of the poppyspecific genic SSR markers currently available, the aim of our study was to develop opium poppy-specific genomic SSR markers with pyrosequencing technology. Pyrosequencing is a low-cost, high-throughput sequencing method which can expedite SSR discovery (Abdelkrim et al. 2009). As part of this goal, we tested a subset of the SSR markers for polymorphism and transferability in opium poppy and related species. This validation of the markers was important to determine their usefulness for fingerprinting, diversity, mapping and breeding studies in opium poppy and related species.

\section{Materials and methods}

Plant materials and DNA isolation

A total of 37 opium poppy accessions from Turkey and seven other Papaver species were used as plant material (Table 1). Eight opium poppy accessions were obtained from the Turkish Soil Product Office (TMO) and 29 accessions were obtained from the Anatolia Agricultural Research Institute (AARI), Eskisehir, Turkey. The related species were used to test transferability of the markers and included Papaver orientale (Iran), P. pseudoorientale (Iran), $P$. bracteatum (Iran), P. rhoeas (Bulgaria), P. umbonatum (Turkey), $P$. nudicaule (Mongolia) and $P$. armeniacum (Armenia). These accessions were obtained from the U.S. Department of AgricultureAgricultural Research Service Plant Germplasm Inspection Station, Beltsville MD, USA. For genomic DNA isolation, each accession was planted in seedling plates. Plants were grown in the greenhouse (24-25 ${ }^{\circ} \mathrm{C}$, approximately $33 \%$ humidity). Total genomic DNA was isolated from leaf tissue bulked from ten plants per accession using a CTAB method (Doyle and Doyle 1990). 
Table 1 Opium poppy accessions and Papaver species used in the study

\begin{tabular}{|c|c|c|c|}
\hline Name & Source & Location & $\begin{array}{l}\text { Landrace/cultivar/ } \\
\text { species }\end{array}$ \\
\hline 1290 & AARI & - & Cultivar \\
\hline 1061 & AARI & - & Cultivar \\
\hline 1259 & AARI & - & Cultivar \\
\hline 1065 & AARI & - & Cultivar \\
\hline Kemerkaya & AARI & - & Cultivar \\
\hline Tinaztepe & AARI & - & Cultivar \\
\hline Zaferyolu & AARI & - & Cultivar \\
\hline Anayurt & AARI & - & Cultivar \\
\hline Afyon95 & AARI & - & Cultivar \\
\hline Ofis3 & TMO & - & Cultivar \\
\hline Ofis4 & TMO & - & Cultivar \\
\hline Ofis8 & TMO & - & Cultivar \\
\hline Ofis95 & TMO & - & Cultivar \\
\hline TM01 & TMO & - & Cultivar \\
\hline TM02 & TMO & - & Cultivar \\
\hline TM03 & TMO & - & Cultivar \\
\hline TM04 & TMO & - & Cultivar \\
\hline 7 & AARI & Sandıklı, Alagöz, Afyon & Landrace \\
\hline 10 & AARI & Çeltik, Burdur & Landrace \\
\hline 14 & AARI & Sivas & Landrace \\
\hline 15 & AARI & Koçyatağı, Şuhut, Afyon & Landrace \\
\hline 19 & AARI & Dişli, Afyon & Landrace \\
\hline 22 & AARI & Anayurt, Şuhut, Afyon & Landrace \\
\hline 32 & AARI & Afyon & Landrace \\
\hline 33 & AARI & Ekinhisar, Sand1klı, Afyon & Landrace \\
\hline 37 & AARI & Höyüklü, Yalvaç, Isparta & Landrace \\
\hline 45 & AARI & Simav, Kütahya & Landrace \\
\hline 59 & AARI & Sülümenli, Afyon & Landrace \\
\hline 60 & AARI & Koçyatağı, Afyon & Landrace \\
\hline 61 & AARI & Şuhut, Afyon & Landrace \\
\hline 67 & AARI & Alacami, Sandıklı, Afyon & Landrace \\
\hline 76 & AARI & Göğen, Uşak & Landrace \\
\hline 89 & AARI & Güre, Uşak & Landrace \\
\hline 92 & AARI & Bolvadin, Afyon & Landrace \\
\hline 95 & AARI & Acıpayam, Denizli & Landrace \\
\hline 96 & AARI & Kütahya & Landrace \\
\hline 103 & AARI & Çay, Afyon & Landrace \\
\hline PI 229617 & AARI & Iran & P. orientale \\
\hline PI 381612 & AARI & Iran & P. pseudoorientale \\
\hline PI 414784 & AARI & Iran & P. bracteatum \\
\hline W6 10919 & AARI & Bulgaria & P. rhoeas \\
\hline W6 11444 & AARI & Turkey & P. umbonatum \\
\hline W6 18131 & AARI & Mongolia & P. nudicaule \\
\hline W6 23866 & AARI & Armenia & P. armeniacum \\
\hline
\end{tabular}


DNA sequencing

For sequencing, total genomic DNA of $P$. somniferum cv. 'Kemerkaya' was extracted using the Wizard Magnetic 96 Plant System (Promega Corp., Madison, WI) with the Beckman Coulter Biomek NX Workstation according to the manufacturer's instructions. Pyrosequencing was done with a Roche 454 GS-FLX sequencer and was performed by 454 Lifesciences Corp. (Branford, CT).

Data acquisition and pre-processing

The adapter and linker sequences were removed to facilitate genome assembly. Following this, the Standard Flowgram Format (SFF) data was converted to separate FASTA (Lipman and Pearson 1985) and quality files because most assembly tools cannot directly work on SFF files (Kumar and Blaxter 2010). The conversion was performed using an open source package of tools written in Python language, which is available at http://bioinf.comav.upv.es/seq_crumbs/ download.html. We used the seq_crumbs tool from the package to perform the conversion with the default settings. The resulting FASTA and FASTQ format files were suitable for sequence assembly.

\section{Sequence assembly}

MIRA, a whole genome shotgun and EST sequence assembler (Chevreux et al. 2004), was used for sequence assembly because it allowed us to customize the assembly process in great detail and led to the best assembly among more than 100 trials with MIRA and four other assembly tools (Gultekin and Allmer, in preparation). Assembly quality was based on various parameters, such as the weighted median of contig lengths (N50), a commonly used measure. The most successful assembly by MIRA used non-default parameters which are described in Electronic Supplementary Material (ESM) 1. The sequences will be provided in a future publication as an annotated draft genome (Gultekin et al. in preparation).

\section{SSR detection and primer design}

The analysis of SSRs of the contig assemblies was performed with our in-house tool SiSeeR (http:// bioinformatics.iyte.edu.tr/index.php?n=Softwares.Si
SeeRHelp) (Gultekin and Allmer, in preparation). The minimum number of repeats needed to identify perfect SSRs were: ten mononucleotide, six dinucleotide, four trinucleotide, four tetranucleotide, three pentanucleotide and three hexanucleotide repeats. Primer design was performed with the Primer3 (Rozen and Skaletsky 2000) (http://frodo.wi.mit.edu/) console application. A total of 19,046 contig sequences yielding 23,427 SSR sequences were converted from FASTA to the default Primer3 input format Boulder-IO. The Primer3 settings, which differed from the default settings, are described in ESM 1. In order to produce primers flanking the SSR sequences, Primer3's SEQUENCE_ TEMPLATE switch was enabled, and values for the start and end positions of each SSR were generated. SSR and primer design data are available at http:// plantmolgen.iyte.edu.tr/research/.

\section{SSR amplification}

Amplification of the opium poppy DNA with genomic SSR primers was carried out in $25-\mu$ reaction mixtures containing $1 \times$ PCR buffer, $3 \mathrm{mM} \mathrm{MgCl} 2,0.125 \mathrm{mM}$ deoxyribonucleotide triphosphates (dNTPs), $1 \mathrm{U}$ Taq Polymerase, 2 pmol forward and reverse primers and 80 ng template DNA. The PCR cycling profile consisted of one cycle of $5 \mathrm{~min}$ at $94{ }^{\circ} \mathrm{C}$, followed by 35 cycles of $45 \mathrm{~s}$ at $94{ }^{\circ} \mathrm{C}, 1 \mathrm{~min}$ at $55^{\circ} \mathrm{C}$ (annealing) and $1 \mathrm{~min}$ at $72{ }^{\circ} \mathrm{C}$, with a final extension step of $5 \mathrm{~min}$ at $72{ }^{\circ} \mathrm{C}$. To prepare the PCR product for analysis by capillary electrophoresis, $3 \mu \mathrm{l}$ of the PCR product was added to $27 \mu \mathrm{l}$ of sample loading buffer (Beckman Coulter, Brea, CA). A size standard $(0.5 \mu \mathrm{l}, 600 \mathrm{bp}$; (Beckman Coulter) was used per reaction in all runs. The mixture for each accession was then run on a Beckman CEQ8800 capillary electrophoresis device using the frag 3 method (capillary temperature $50{ }^{\circ} \mathrm{C}$, denaturation $90{ }^{\circ} \mathrm{C}$ for $120 \mathrm{~s}$, injection voltage $2.0 \mathrm{kV}$ for $3 \mathrm{~s}$, separation voltage $4.8 \mathrm{kV}$ for $60 \mathrm{~min}$ ).

\section{Data analysis}

Amplified SSR loci were scored as present (1) or absent (0). Rare PCR fragments $(<4$ occurrences) were excluded from analysis because they might be unreliable. The binary data were used to calculate the PIC value for each marker fragment based on the formula: $\mathrm{PIC}_{\mathrm{i}}=2 f_{\mathrm{i}}\left(1-f_{\mathrm{i}}\right)$ where $f_{\mathrm{i}}$ is the frequency of band presence (Roldan-Ruiz et al. 2000). A 
dissimilarity matrix generated using the Dice coefficient was used to construct a dendrogram with the unweighted neighbor joining method using the Darwin computer program (Perrier and Jacquemoud-Collet 2006). The correlation of the dissimilarity matrix and the dendrogram was calculated using a Mantel test.

\section{Results}

Sequence assembly, SSR identification and primer design

Pyrosequencing resulted in $1,244,412$ sequence reads covering more than $695 \mathrm{Mb}$ (Table 2). After removal of the linkers and adapters, nearly $475 \mathrm{Mb}$ remained, with an average sequence read length of 380.4 nucleotides (nt). A total of 649,267 reads representing $52 \%$ of all sequences were assembled into 166,724 contigs encompassing $105 \mathrm{Mb}$ of the opium poppy genome. The weighted median contig length (N50) of the assembly was $913 \mathrm{nt}$. Only contigs were used for SSR detection because singlet reads were shorter and, therefore, would not be as useful for designing effective primers.

A total of 23,283 non-redundant SSRs were identified in 18,944 contigs ( $11.3 \%$ of total contigs). Approximately $16 \%(3,135)$ of contigs contained more than one SSR (ESM 2). A maximum of ten and 11 different SSRs were identified in one contig each. SSR length ranged from 3 to $226 \mathrm{nt}$, with an average length of $13.4 \pm 0.03 \mathrm{nt}$. The most abundant repeat types were trinucleotide SSRs, which accounted for $49.0 \%$ of all SSRs (Table 3), followed by tetranucleotide repeats $(27.9 \%)$. The remaining repeat types each accounted for $<10 \%$ of the SSRs. Some motifs were more common than others (Table 4). The majority $(82.2 \%)$ of mononucleotide repeats consisted of A/T repeats. AT/TA was the most abundant
Table 3 Simple sequence repeat types in the opium poppy contig sequences

\begin{tabular}{lcc}
\hline Motif length & Number of SSRs & Frequency (\%) \\
\hline Mononucleotide & 842 & 3.6 \\
Dinucleotide & 2,114 & 9.1 \\
Trinucleotide & 11,406 & 49.0 \\
Tetranucleotide & 6,493 & 27.9 \\
Pentanucleotide & 1,600 & 6.9 \\
Hexanucleotide & 828 & 3.6 \\
Total & 23,283 & 100 \\
\hline
\end{tabular}

SSR Simple sequence repeat

dinucleotide repeat motif and accounted for $50.4 \%$ of these repeats. AAG/TTC was the most abundant $(19.7 \%)$ trinucleotide repeat. AT-rich repeats were also most common repeats in tetra-, penta- and hexanucleotide SSRs. Primers were designed for 23,126 SSRs; only $1.3 \%$ of the SSR sequences were unsuitable for primer design.

Polymorphism, validation and transferability of genomic SSR markers

A total of 100 genomic SSR primer pairs were first tested on five opium poppy accessions (1290, 1061, 1259, 1065, cv. 'Kemerkaya'). Of these primers, 96 (96\%) amplified products. A total of 53 genomic SSR markers which showed clear amplification following electrophoresis on agarose gel (ESM 3) were then tested in the 37 opium poppy accessions and seven Papaver species for determination of polymorphism and transferability (Table 1). Seventeen of the opium poppy accessions were named varieties while the others were landraces collected in Turkey. The 53 SSR primers generated 209 polymorphic fragments in all accessions and 90 polymorphic fragments in $P$. somniferum accessions (Table 5). The average

Table 2 Sequence preprocessing and assembly statistics

\begin{tabular}{llll}
\hline Parameter & Raw sequences & Cleaned sequences & Contigs \\
\hline Total no. sequences & $1,244,412$ & $1,244,412$ & 166,724 \\
Minimum sequence length (nt) & 52 & 40 & 40 \\
Maximum sequence length (nt) & 1,201 & 764 & 42,888 \\
Average sequence length (nt) & $558.7 \pm 66$ & $380.4 \pm 142.5$ & $731.0 \pm 376.8$ \\
Total no. bases & $695,339,138$ & $474,398,321$ & $105,303,268$ \\
\hline
\end{tabular}


Table 4 Most abundant SSR motif types in contigs

\begin{tabular}{lcl}
\hline SSR motif & $\begin{array}{l}\text { Number } \\
\text { of SSRs }\end{array}$ & $\begin{array}{l}\text { Percentage of } \\
\text { SSR motifs }\end{array}$ \\
\hline A/T & 692 & 82.2 \\
C/G & 150 & 17.8 \\
AT/TA & 1,066 & 50.4 \\
AG/TC & 383 & 18.1 \\
AC/TG & 340 & 16.1 \\
CT/GA & 318 & 15.0 \\
AAG/TTC & 2,243 & 19.7 \\
ACC/TGG & 1,381 & 12.1 \\
AAC/TTG & 1,228 & 10.8 \\
AAAT/TTTA & 1,101 & 17.0 \\
AAATA/TTTAT & 300 & 18.8 \\
AAAAAT/TTTTTA & 88 & 10.6 \\
\hline
\end{tabular}

Only motifs comprising more than $10 \%$ of each repeat type are listed

number of amplified fragments per genomic SSR marker was $5 \pm 0.01$, with a range of $1-13$ fragments. A total of 48 SSR primers (95\%) were polymorphic in all accessions, with an average fragment polymorphism of $84 \%$. For all accessions, average PIC values ranged from 0.05 for psgSSR076 to 0.47 for psgSSR022, with an average PIC of 0.19. Fewer (60.4\%) SSR primers showed intraspecific polymorphism in $P$. somniferum, with an average fragment polymorphism of $63 \%$; the average intraspecific PIC value decreased to 0.17 . Intraspecific PIC values ranged from 0.05 for five different markers to 0.49 for psgSSR22. In all analyses there was no significant correlation between PIC values and SSR motif types or lengths.

To ensure that the expected SSRs were amplified by the primers, we sequenced seven PCR products from cv. 'Kemerkaya'. Only one of the products contained an unexpected SSR. Although these results indicate imperfect validation of the identified SSRs, the fact that the amplification product contained a polymorphic SSR is sufficient for use of this particular primer pair as a molecular marker.

Transferability of the 53 genomic SSR markers was tested in seven Papaver species: P. bracteatum, $P$. pseudoorientale, $P$. orientale, $P$. nudicaule, $P$. armeniacum, $P$. rhoeas and $P$. umbonatum. A high rate of transferability was observed in these species (ESM 4).
All 53 SSR markers yielded PCR products in $P$. pseudoorientale, $52(98 \%)$ yielded PCR products in $P$. bracteatum and $P$. nudicaule, 51 (96\%) markers yielded PCR products in $P$. orientale and armeniacum, 49 (92\%) SSR markers yielded PCR products in $P$. umbonatum, and 47 (88.7\%) SSR markers yielded PCR products in $P$. rhoeas.

Genetic diversity analysis with genomic SSR markers in opium poppy

Low-frequency fragments (observed in $<10 \%$ of poppy accessions) were excluded from all analyses because these low-frequency fragments can be unreliable. A total of 209 high-quality, reproducible polymorphic fragments were used for our diversity analysis of opium poppy and related species. The binary presence/absence data were used to generate a distance matrix using the Dice coefficient to draw a dendrogram employing the unweighted neighborjoining algorithm. As expected, a Mantel test showed a strong correlation $(r=0.998)$ between the distance matrix and dendrogram. Dissimilarity between accessions ranged from 0.008 to 0.48 (52\% similarity), with average dissimilarity of 0.14 (Fig. 1). Dissimilarity between opium poppy and related species ranged from 0.23 to 0.48 . As expected, Papaver species clustered separately from $P$. somniferum accessions. The $P$. somniferum accessions fell into three clusters. Cluster 1 contained 13 landraces and 13 varieties/breeding lines, and the dissimilarity ranged from 0.01 to 0.08 , with an average dissimilarity of 0.04. Cluster 1 had six subclusters (subclusters A-F), with cluster $1 \mathrm{~B}$ containing only named varieties and cluster $1 \mathrm{C}$ containing only landraces of $P$. somniferum; varieties and landraces were intermixed in the other subclusters. Cluster 2 contained eight opium poppy accessions (four landraces and four varieties) and had an average dissimilarity of 0.06 , with minimum and maximum dissimilarities of 0.03 and 0.16 , respectively. Cluster 3 comprised three opium poppy landraces $(59,22$ and 76$)$ which were the most genetically distinct opium poppy accessions in the study. Clustering of the Papaver species did not match that obtained with the internal transcribed spacer nuclear ribosomal DNA and plastid trnL sequences (Carolan et al. 2006). 
Table 5 Polymorphism information content of genomic markers

\begin{tabular}{|c|c|c|c|c|c|}
\hline \multirow[t]{2}{*}{ SSR marker } & \multirow[t]{2}{*}{ Repeat motif } & \multicolumn{2}{|l|}{ All accessions } & \multicolumn{2}{|l|}{ P. somniferum } \\
\hline & & $\begin{array}{l}\text { Number of } \\
\text { polymorphic } \\
\text { fragments/total } \\
\text { no. fragments }(\%)\end{array}$ & $\mathrm{PIC}^{\mathrm{a}}$ & $\begin{array}{l}\text { Number of } \\
\text { polymorphic } \\
\text { fragments/total } \\
\text { no. fragments }(\%)\end{array}$ & $\mathrm{PIC}^{\mathrm{a}}$ \\
\hline psgSSR002 ${ }^{\mathrm{b}}$ & $(\mathrm{ATG} / \mathrm{TAC})_{4}$ & $5 / 7(71)$ & $0.12 \pm 0.02$ & 1/7 (14) & 0.06 \\
\hline psgSSR005 & $(\mathrm{CATCTG} / \mathrm{GTAGC})_{3}$ & $2 / 2(100)$ & $0.21 \pm 0.01$ & $2 / 2(100)$ & $0.21 \pm 0.02$ \\
\hline psgSSR006 & $(\mathrm{AACA} / \mathrm{TTGT})_{3}$ & $4 / 5(80)$ & $0.31 \pm 0.06$ & $4 / 5(80)$ & $0.25 \pm 0.09$ \\
\hline psgSSR008 ${ }^{\mathrm{b}}$ & $(\mathrm{AAG} / \mathrm{TTC})_{8}$ & $8 / 8(100)$ & $0.28 \pm 0.05$ & $6 / 8(75)$ & $0.20 \pm 0.08$ \\
\hline $\operatorname{psgSSR013}{ }^{\mathrm{b}}$ & $(\mathrm{ATA} / \mathrm{TAT})_{4}$ & 13/13 (100) & $0.18 \pm 0.01$ & 1/8 (13) & 0.05 \\
\hline psgSSR015 & $(\mathrm{CAG} / \mathrm{GTC})_{4}$ & $5 / 6(83)$ & $0.17 \pm 0.03$ & $0 / 5(0)$ & 0 \\
\hline psgSSR021 & $(\mathrm{TA} / \mathrm{AT})_{6}$ & $3 / 3(100)$ & $0.15 \pm 0.09$ & $3 / 3(100)$ & $0.15 \pm 0.10$ \\
\hline psgSSR022 & $(\mathrm{TGG} / \mathrm{ACC})_{4}$ & $1 / 3(33)$ & 0.47 & $1 / 2(50)$ & 0.49 \\
\hline psgSSR023 ${ }^{\mathrm{b}}$ & $(\mathrm{TGTCA} / \mathrm{ACAGT})_{3}$ & $7 / 7(100)$ & $0.29 \pm 0.05$ & $5 / 7(71)$ & $0.22 \pm 0.09$ \\
\hline psgSSR024 & $(\mathrm{TTC} / \mathrm{AAG})_{6}$ & $9 / 9(100)$ & $0.16 \pm 0.03$ & $3 / 5(60)$ & $0.1 \pm 0.03$ \\
\hline psgSSR027 & $(\mathrm{TA} / \mathrm{AT})_{6}$ & 1/3 (33) & 0.20 & $0 / 2(0)$ & 0 \\
\hline psgSSR029 & $(\mathrm{TCAT} / \mathrm{AGTA})_{3}$ & $0 / 2(0)$ & 0 & $0 / 2(0)$ & 0 \\
\hline psgSSR030 & $(\mathrm{AACA} / \mathrm{TTGT})_{3}$ & $1 / 1(100)$ & 0.13 & 1/1 (100) & 0.10 \\
\hline psgSSR033 & $(\mathrm{CAAA} / \mathrm{GTTT})_{3}$ & $3 / 4(75)$ & $0.22 \pm 0.02$ & $1 / 3(33)$ & 0.10 \\
\hline psgSSR034 & $(\mathrm{TGG} / \mathrm{ACC})_{4}$ & $4 / 5(80)$ & $0.21 \pm 0.09$ & $2 / 3(67)$ & $0.27 \pm 0.22$ \\
\hline psgSSR036 & $(\mathrm{CCAA} / \mathrm{GGTT})_{3}$ & $1 / 3(33)$ & 0.20 & $0 / 6(0)$ & 0 \\
\hline $\operatorname{psgSSR} 037^{\mathrm{b}}$ & $(\mathrm{GAA} / \mathrm{CTT})_{10}$ & 9/9 (100) & $0.20 \pm 0.06$ & $5 / 9(56)$ & $0.25 \pm 0.08$ \\
\hline psgSSR038 & $(\mathrm{TGAT} / \mathrm{ACTA})_{3}$ & $6 / 7(86)$ & $0.24 \pm 0.04$ & $2 / 4(50)$ & $0.23 \pm 0$ \\
\hline psgSSR039 & $(\mathrm{ACAAC} / \mathrm{TGTTG})_{4}$ & $11 / 11(100)$ & $0.21 \pm 0.02$ & $5 / 10(50)$ & $0.18 \pm 0.01$ \\
\hline psgSSR040 & $(\mathrm{TGT} / \mathrm{ACA})_{4}$ & $3 / 4(75)$ & $0.18 \pm 0.03$ & $0 / 3(0)$ & 0 \\
\hline $\operatorname{psgSSR041^{\mathrm {b}}}$ & $(\text { TCTTA/AGAAT })_{3}$ & 10/10 (100) & $0.29 \pm 0.03$ & 10/10 (100) & $0.13 \pm 0.04$ \\
\hline psgSSR042 & $(\mathrm{TTCA} / \mathrm{AAGT})_{4}$ & $5 / 5(100)$ & $0.16 \pm 0.03$ & $0 / 4(0)$ & 0 \\
\hline psgSSR046 & $(\text { TGAT/ACTA })_{3}$ & $3 / 4(75)$ & $0.17 \pm 0.07$ & $2 / 4(50)$ & $0.19 \pm 0$ \\
\hline psgSSR047 & $(\mathrm{AGA} / \mathrm{TCT})_{4}$ & $5 / 5(100)$ & $0.19 \pm 0.08$ & $2 / 5(40)$ & $0.30 \pm 0.20$ \\
\hline psgSSR050 & $(\mathrm{GAA} / \mathrm{CTT})_{4}$ & $0 / 3(0)$ & 0 & $0 / 3(0)$ & 0 \\
\hline psgSSR053 & $(\mathrm{TA} / \mathrm{AT})_{7}$ & $2 / 5(40)$ & $0.12 \pm 0.08$ & $1 / 5(20)$ & 0.05 \\
\hline psgSSR054 & $(\mathrm{TCGT} / \mathrm{AGCA})_{3}$ & 4/4 (100) & $0.13 \pm 0.02$ & $0 / 2(0)$ & 0 \\
\hline psgSSR055 & $(\mathrm{TC} / \mathrm{AG})_{7}$ & $3 / 5(60)$ & $0.13 \pm 0.05$ & 0/4 (0) & 0 \\
\hline psgSSR058 & $(\mathrm{AATA} / \mathrm{TTAT})_{3}$ & $1 / 2(50)$ & 0.13 & $0 / 2(0)$ & 0 \\
\hline psgSSR059 & AAAT/TTTA) $)_{3}$ & $5 / 6(83)$ & $0.20 \pm 0.02$ & 0/1 (0) & 0 \\
\hline psgSSR060 & $(\mathrm{TCT} / \mathrm{AGA})_{4}$ & $2 / 3(67)$ & $0.30 \pm 0.17$ & $1 / 2(50)$ & 0.44 \\
\hline psgSSR061 & $(\mathrm{AAAT} / \mathrm{TTTA})_{3}$ & $3 / 3(100)$ & $0.27 \pm 0.02$ & $3 / 3(100)$ & $0.1 \pm 0.05$ \\
\hline psgSSR062 & $(\mathrm{AGAC} / \mathrm{TCTG})_{3}$ & $2 / 3(67)$ & $0.07 \pm 0.02$ & $0 / 3(0)$ & 0 \\
\hline psgSSR064 & $(\mathrm{ATA} / \mathrm{TAT})_{4}$ & $1 / 1(100)$ & 0.20 & 1/1 (100) & 0.05 \\
\hline $\operatorname{psgSSR067} 7^{\mathrm{b}}$ & $(\mathrm{TTCT} / \mathrm{AAGA})_{3}$ & 9/9 (100) & $0.23 \pm 0.02$ & $3 / 7(43)$ & $0.19 \pm 0.07$ \\
\hline psgSSR068 & $(\mathrm{TTCT} / \mathrm{AAGA})_{3}$ & 0/1 (0) & 0 & $0 / 1(0)$ & 0 \\
\hline psgSSR069 & $(\mathrm{CAAT} / \mathrm{GTTA})_{4}$ & $5 / 6(83)$ & $0.20 \pm 0.02$ & $0 / 5(0)$ & 0 \\
\hline psgSSR070 & $(\mathrm{ATT} / \mathrm{TAA})_{5}$ & $2 / 2(100)$ & $0.22 \pm 0.05$ & $0 / 1(0)$ & 0 \\
\hline psgSSR071 & (TATTC/ATAAG) & $2 / 2(100)$ & $0.13 \pm 0.00$ & $0 / 2(0)$ & 0 \\
\hline $\operatorname{psgSSR} 074^{\mathrm{b}}$ & $(\mathrm{GTTT} / \mathrm{CAAA})_{3}$ & $12 / 12(100)$ & $0.22 \pm 0.03$ & 11/11 (100) & $0.19 \pm 0.03$ \\
\hline psgSSR076 & $(\mathrm{AATG} / \mathrm{TTAC})_{3}$ & $1 / 1(100)$ & 0.05 & $1 / 1(100)$ & 0.05 \\
\hline
\end{tabular}


Table 5 continued

\begin{tabular}{|c|c|c|c|c|c|}
\hline \multirow[t]{2}{*}{ SSR marker } & \multirow[t]{2}{*}{ Repeat motif } & \multicolumn{2}{|l|}{ All accessions } & \multicolumn{2}{|l|}{ P. somniferum } \\
\hline & & $\begin{array}{l}\text { Number of } \\
\text { polymorphic } \\
\text { fragments/total } \\
\text { no. fragments }(\%)\end{array}$ & $\mathrm{PIC}^{\mathrm{a}}$ & $\begin{array}{l}\text { Number of } \\
\text { polymorphic } \\
\text { fragments/total } \\
\text { no. fragments }(\%)\end{array}$ & $\mathrm{PIC}^{\mathrm{a}}$ \\
\hline psgSSR077 & $(\mathrm{ATC} / \mathrm{TAG})_{4}$ & $5 / 5(100)$ & $0.14 \pm 0.04$ & $1 / 4(25)$ & 0.05 \\
\hline psgSSR078 & $(\text { GTATT/CATAA })_{3}$ & $3 / 4(75)$ & $0.15 \pm 0.02$ & $1 / 3(33)$ & 0.15 \\
\hline psgSSR079 & $(\mathrm{GGAA} / \mathrm{CCTT})_{3}$ & $0 / 2(0)$ & 0 & $0 / 2(0)$ & 0 \\
\hline psgSSR080 & $(\mathrm{GGAA} / \mathrm{CCTT})_{3}$ & $6 / 6(100)$ & $0.29 \pm 0.05$ & 4/4 (100) & $0.29 \pm 0.08$ \\
\hline psgSSR082 & $(\mathrm{AAT} / \mathrm{TTA})_{4}$ & $1 / 2(50)$ & 0.20 & $0 / 2(0)$ & 0 \\
\hline psgSSR085 & $(\mathrm{ATTT} / \mathrm{TAAA})_{3}$ & $5 / 5(100)$ & $0.18 \pm 0.04$ & $1 / 4(25)$ & 0.1 \\
\hline psgSSR90 & $(\mathrm{TGT} / \mathrm{ACA})_{4}$ & $5 / 6(83)$ & $0.16 \pm 0.04$ & $0 / 2$ & 0 \\
\hline psgSSR093 & $(\mathrm{AAT} / \mathrm{TTA})_{4}$ & $2 / 2(100)$ & $0.07 \pm 0.02$ & $2 / 2(100)$ & $0.05 \pm 0$ \\
\hline psgSSR094 & $(\mathrm{GCA} / \mathrm{CGT})_{4}$ & $3 / 3(100)$ & $0.28 \pm 0.03$ & $3 / 3(100)$ & $0.15 \pm 0.04$ \\
\hline psgSSR098 & $(\text { TGTTG/ACAAC) })_{3}$ & $0 / 1(0)$ & 0 & 0/1 (0) & 0 \\
\hline psgSSR099 & $(\mathrm{ATC} / \mathrm{TAG})_{4}$ & $2 / 4(50)$ & $0.22 \pm 0.05$ & $0 / 2(0)$ & 0 \\
\hline psgSSR100 & $(\mathrm{GTG} / \mathrm{CAC})_{4}$ & $4 / 5(80)$ & $0.14 \pm 0.04$ & $1 / 4(25)$ & 0.15 \\
\hline
\end{tabular}

${ }^{\text {a }}$ Polymorphic information content (PIC) is presented as the average \pm standard error

b Markers that amplified more than one locus in P. somniferum

\section{Discussion}

Simple sequence repeat markers are frequently used in plant genetic studies because they are easy to amplify, highly reproducible, polymorphic and often multiallelic (Varshney et al. 2005). In the past, detection of genomic SSRs and subsequent conversion to markers was expensive and time-consuming, involving the construction and screening of genomic DNA libraries followed by the sequencing of candidate clones (Zalapa et al. 2012). The advent of next-generation sequencing technologies, such as pyrosequencing, has redefined this process. Much of the work is now performed in silico with wet laboratory experiments confined to sequencing and SSR validation. As a result, many more SSR markers can be identified quickly and at a lower cost. This approach is especially promising for minor crop, tree and weed species that have been often ignored in the area of molecular marker development [e.g. cranberry (Zhu et al. 2012), black alder (Lepais and Bacles 2011 and waterhemp (Lee et al. 2009)].

Distribution of SSRs in the opium poppy genome

We used high-throughput pyrosequencing to develop genomic SSR markers in opium poppy. The assembly of the relatively long sequences (average length $731 \mathrm{nt}$ in assembly) resulted in more than 160,000 contigs covering $105 \mathrm{Mb}$ of the opium poppy genome. The contigs provided $2.83 \%$ coverage of the opium poppy genome, which has been reported to contain 3,724 Mb of DNA (Bennett and Smith 1976). As expected, this is much higher than the coverage obtained from EST unigene assembly (0.4\%; Selale et al. 2013) and provided a sevenfold increased coverage of the opium poppy genome. Average density of genomic SSRs was one SSR every $4.5 \mathrm{~kb}$ of genomic DNA, which is in the range expected for plant species (Cavagnaro et al. 2010). Genomic SSRs occurred less frequently than non-redundant genic SSRs (every $3.6 \mathrm{~kb}$ in EST sequences; Selale et al. 2013) in the opium poppy genome. This difference is in concurrence with the results of Morgante et al. (2002) and of the same magnitude (1.25-fold) as the difference in frequency observed in rice, soybean and sorghum (1.2- to 2-fold, Cavagnaro et al. 2010).

In our study, trinucleotides were the most prevalent SSR type in opium poppy genomic DNA, accounting for nearly half $(48.7 \%)$ of all SSRs identified. Trinucleotide repeats are also the most frequently identified SSR type in Arabidopsis, rice, soybean and sorghum genomic DNA (Cavagnaro et al. 2010). The 


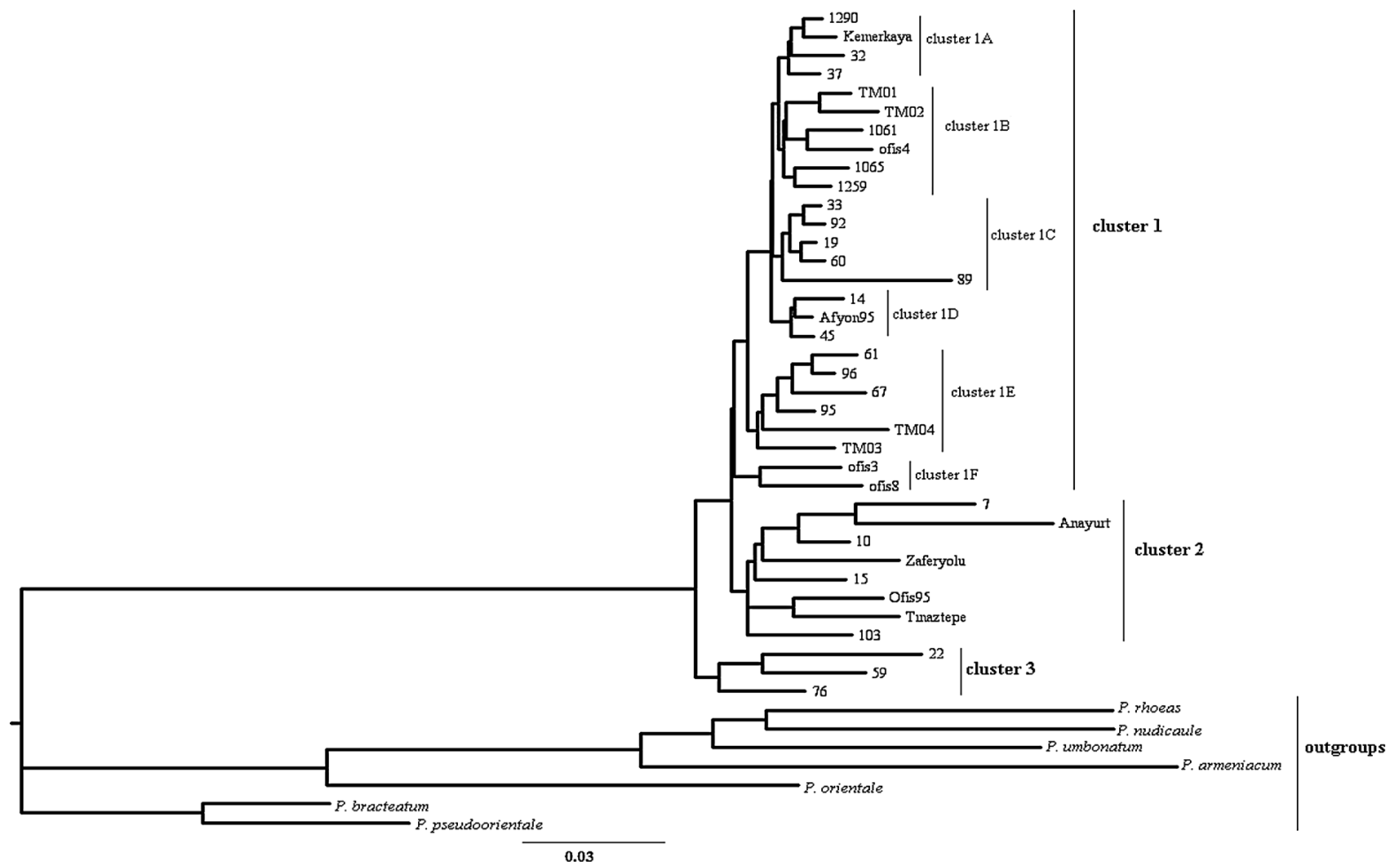

Fig. 1 Unweighted neighbor-joining dendrogram of the poppy accessions constructed by genomic simple sequence repeat markers

frequency distribution of the other SSR types in opium poppy also matched that of other species, with the frequency being tetranucleotide $>$ dinucleotide $>$ pentanucleotide (Cavagnaro et al. 2010). The frequencies of SSRs in opium poppy genomic DNA were similar to those observed in EST sequences, with the exception of mononucleotide repeats which ranked fifth in genomic DNA and third in genic DNA (Selale et al. 2013). The abundance of trinucleotides in genic DNA is hypothesized to be the result of purifying selection which eliminates any SSRs causing frameshift mutations. However, it is unknown if selection is involved in the distribution of SSR types in genomic DNA.

Among the different motif types, AT-rich motifs were often the most common. This has also been observed in genomic DNA of other dicot plant species (Cavagnaro et al. 2010) as well as in opium poppy genic DNA (Selale et al. 2013). AAG/TTC was the most common trinucleotide motif, which is in agreement with results reported for other dicots, including cucumber, soybean, Arabidopsis and grape (Cavagnaro et al. 2010). AAG/TTC was also the most frequent trinucleotide detected by Selale et al. (2013) in their study of opium poppy genic sequences and was described as the most frequent genic trinucleotide in plants by Li et al. (2004).

The similarities between genomic and genic SSR types and motifs in opium poppy may, in part, be due to the presence of coding sequences in the genomic DNA contig assembly. In future studies, the contig sequences could be annotated to determine the percentage of protein-coding DNA and to determine any redundancy in the SSRs identified in our two studies (i.e. present study and Selale et al. 2013).

Polymorphism and transferability of genomic SSR markers

Most of the SSR primers (96\%) amplified PCR products. The amplification success of the genomic SSR markers was slightly higher than that for the genic SSR markers ( $82 \%$ ) developed by Selale et al. (2013). A high rate of successful amplification can be due to high-quality sequence data and the appropriate primer parameters, such as high GC content. In our study, the 
genomic SSR markers detected an intermediate level of polymorphism, with an average PIC value of 0.19 among the Papaver species and opium poppy accessions, and a slightly lower level of intraspecific polymorphism (average PIC 0.17). Polymorphism of the genomic SSR markers was lower than that of previously developed genic SSR markers (Lee et al. 2011; Selale et al. 2013). Although genomic SSRs are often reported to have higher levels of polymorphism than genic SSRs (Varshney et al. 2005), Tian et al. (2012) recently showed that genic SSR markers were more polymorphic than genomic SSR markers in Coreoperca whiteheadi.

Many of the genomic SSR markers in our study amplified multiple fragments (average of 5 fragments per marker). This is most likely the result of polyploidy in opium poppy. Papaver somniferum $(2 n=22)$ is an aneuallopolyploid and is hypothesized to have originated from species with $x=7$ (Lavania and Srivastava 1999). Therefore, a single copy SSR locus may amplify up to six fragments. In our study, nine SSR markers (17\%) had more than six fragments, indicating that these SSR markers originate from multiple loci. (These markers are labeled with an asterisk in Table 5). In our study, the number of fragments amplified by genomic SSR markers was slightly higher than that amplified by six genic SSR markers developed by Lee et al. (2011). who obtained an average of $2.8 \pm 0.5$ fragments (mean \pm standard error; range 2-5). However, in their study, Lee et al. (2011) did not use markers that produced more than three fragments, thereby limiting fragment number. These authors also reported that the average fragment number for the genomic SSRs was lower than that for the genic SSRs which amplified an average of 8.4 fragments per SSR (Selale et al. 2013). This result can be explained by the fact that many of the genic SSR markers (23 SSR markers) were multiallelic while only nine genomic SSRs were multiallelic in this study. Additional genic and genomic markers should be tested to determine if this difference is real or a sampling artifact.

High transferability of the genomic SSR markers to related Papaver species was observed, varying from 88.7 to $100 \%$ depending on the species tested. A high transferability rate has also been reported for genic SSR markers in opium poppy (Selale et al. 2013). This high rate of transferability indicates that there are conserved regions among Papaver species. High transferability of both types of SSR markers is valuable for Papaver species given the limited molecular tools available for this genus.

Genetic diversity anaysis with genomic SSR markers

The genomic SSR markers developed in this study can be used in opium poppy identification. Although rare alleles were excluded, a total of 32 SSR primers $(60.4 \%)$ identified in our study were useful for Turkish opium poppy identification. Retesting of rare alleles is needed to confirm whether or not these are reproducible and suitable for opium poppy identification. Dendrogram analysis also showed that genomic SSR markers were suitable for differentiating opium poppy from Papaver species. Thus, these markers can be used to analyze intra- and interspecific genetic diversity of opium poppy. Landraces and named varieties were intermixed in the dendrogram of genomic SSR markers. This differs from the results reported by Selale et al. (2013) obtained with nearly the same accessions using genic SSR markers in which named varieties clustered separately from landraces. This difference may be the result of artificial selection pressure on genic SSRs. Chabane et al. (2005) reported that genic SSR markers provided clearer separation between wild and cultivated barley than genomic SSR markers, as was observed in our studies. Although the topology of the dendrogram for genomic SSR markers was different from the dendrogram based on genic SSR markers, Mantel test results showed that there was a very high correlation $(r=0.98)$ between the distance matrices for the two marker types. Therefore, genomic and genic SSR markers give consistent results in opium poppy.

In conclusion, pyrosequencing and mining of the opium poppy genome allowed identification of numerous SSR repeats which can be exploited for marker development. These markers are highly transferable within the genus Papaver and are an important addition to the repertoire of molecular tools available for genetic studies and breeding in opium poppy.

Acknowledgments The authors thank Dr. Hüseyin Camci, Dr. Arzu Köse and Dr. Ferda Kosar from the Anatolia Agricultural Research Institute for providing plant material. We are also grateful to Ali Üncü and Ayşe Dülger Üncü for SSR validation by sequencing. This study was supported by The Scientific and Technological Research Council of Turkey (TUBITAK) project no. 1090797. 


\section{References}

Abdelkrim J, Robertson BC, Stanton JA, Gemmell NJ (2009) Fast cost-efective development of species-specific microsatalite markers by genomic sequencing. Biotechniques 46:185-192. doi:10.2144/000113084

Acharya HS, Sharma V (2009) Molecular characterization of opium poppy (Papaver somniferum) germplasm. Am J Infect Dis 5:148-153

Bennett MD, Smith JB (1976) Nuclear DNA amounts in angiosperms. Philos Trans R Soc Lond B Biol Sci 274:227-274

Carolan JC, Hook ILI, Chase MW, Kadereit JW, Hodkinson TR (2006) Phylogenetics of Papaver and related genera based on DNA sequences from ITS nuclear ribosomal DNA and plastid $t r n L$ intron and $t r n L-F$ intergenic spacers. Ann Bot 98:141-155. doi:10.1093/aob/mcl079

Cavagnaro PF, Douglas AS, Yang L, Simon PW, Harkins TT, Kodira CD, Huang S, Weng Y (2010) Genome-wide characterization of simple sequence repeats in cucumber (Cucumis sativus L.). BMC Genom 11:569. doi:10.1186/ 1471-2164-11-569

Chabane K, Ablett GA, Cordeiro GM, Valkoun J, Henry RJ (2005) EST versus genomic derived microsatellite markers for genotyping wild and cultivated barley. Gen Resour Crop Evol 52:903-909. doi:10.1007/s10722-003-6112-7

Chevreux B, Pfisterer T, Drescher B, Driesel AJ, Müller WEG, Wetter T, Suhai S (2004) Using the miraEST assembler for reliable and automated mRNA transcript assembly and SNP detection in sequenced ESTs. Genome Res 14:11471159. doi:10.1101/gr.1917404

Dittbrenner A, Lohwasser U, Mock HP, Börner A (2008) V International symposium on the taxonomy of cultivated plants. In: Groendijk-Wilders N, Alexander C, Berg RGVD, Hetterscheid WLA (eds) Molecular and phytochemical studies of Papaver somniferum in the context of infraspecific classification. ISHS Acta Horticulturae, Wageningen, pp 81-88

Doyle JJ, Doyle JE (1990) Isolation of plant DNA from fresh tissue. Focus 12:13-15

Ellis JR, Burke JM (2007) EST-SSRs as a resource for population genetic analyses. Heredity 99:125-132. doi:10.1038/ sj.hdy. 6801001

Facchini PJ, De Luca V (2008) Opium poppy and Madagascar periwinkle: model non-model systems to investigate alkaloid biosynthesis in plants. Plant J Cell Mol Biol 54: 763-784. doi:10.1111/j.1365-313X.2008.03438.x

Gumuscu A, Arslan N (2008) Researches on heterosis on yield and yield components of some poppy. Tarım Bilimleri Dergisi 14:365-373

Jones N, Ougham H, Thomas H, Pasakinskiene I (2009) Markers and mapping revisited: finding your gene. New Phytol 183:935-966. doi:10.1111/j.1469-8137.2009.02933.x

Kumar S, Blaxter ML (2010) Comparing de novo assemblers for 454 transcriptome data. BMC Genom 11:571. doi:10.1186/ 1471-2164-11-571

Lavania UC, Srivastava S (1999) Quantitative delineation of karyotype variation in Papaver as an measure of phylogenetic differentiation origin. Curr Sci 77:429-435

Lee RM, Thimmapuram J, Thinglum KA, Gong G, Hernandez AG, Wright CL, Kim RW, Mikel MA, Tranel PJ (2009)
Sampling the waterhemp (Amaranthus tuberculatus) genome using pyrosequencing technology. Weed Sci 57:463-469. doi:http://dx.doi.org/10.1614/WS-09-021.1

Lee EJ, Jin GN, Lee KL, Han MS, Lee YH, Yang MS (2011) Exploiting expressed sequence tag databases for the development and characterization of gene-derived simple sequence repeat markers in the opium poppy (Papaver somniferum L.) for forensic applications. J Forensic Sci 56:1131-1135. doi:10.1111/j.1556-4029.2011.01810.x

Lepais O, Bacles CFE (2011) De novo discovery and multiplexed amplification of microsatellite markers for black alder (Alnus glutinosa) and related species using SSRenriched shotgun pyrosequencing. J Hered 102:627-632. doi:10.1093/jhered/esr062

Li YC, Korol AB, Fahima T, Beiles A, Nevo E (2002) Microsatellites: genomic distribution, putative functions and mutational mechanisms: a review. Mol Ecol 11:2453-2465. doi:10.1046/j.1365-294X.2002.01643.x

Li YC, Korol AB, Fahima T, Nevo E (2004) Microsatellites within genes: structure, function, and evolution. Mol Biol Evol 21:991-1007

Lipman DJ, Pearson WR (1985) Rapid and sensitive protein similarity searches. Science 227:1435-1441. doi:10.1126/ science. 2983426

Morgante M, Hanafey M, Powell W (2002) Microsatellites are preferentially associated with nonrepetitive DNA in plant genomes. Nat Genet 30:194-200. doi:10.1038/ng822

Parmaksiz I, Ozcan S (2011) Morphological, chemical and molecular analyses of Turkish Papaver accessions (Sect. Oxytona). Turk J Bot 35:1-16. doi:10.3906/bot-1003-39

Perrier X, Jacquemoud-Collet JP (2006) DARwin software. http://darwin.cirad.fr/darwin

Roldan-Ruiz I, Dendauw J, Bockstaele EV, Depicker A, Loose MD (2000) AFLP markers reveal high polymorphic rates in ryegrasses (Lolium spp.). Mol Breed 6:125-134. doi:10. 1023/A:1009680614564

Rozen S, Skaletsky HJ (2000) Bioinformatics methods and protocols: methods in molecular biology. In: Krawetz S, Misener $\mathrm{S}$ (eds) Primer3 on the WWW for general users and for biologist programmers. Humana Press, Totowa, pp 365-386

Saunders JA, Pedroni MJ, Penrose LDJ, Fist AJ (2001) AFLP analysis of opium poppy. Crop Sci 41:1596-1601. doi:10. 2135/cropsci2001.4151596x

Schulz H, Baranska M, Quilitzsch R, Schütze W (2004) Determination of alkaloids in capsules, milk and ethanolic extracts of poppy (Papaver somniferum L.) by ATR-FT-IR and FT-Raman spectroscopy. Analyst 129:917-920. doi:10.1039/B408930H

Selale H, Celik I, Gultekin V, Allmer J, Doganlar S, Frary A (2013) Development of EST-SSR markers for diversity and breeding studies in opium poppy (Papaver somniferum L.). Plant Breed 132:344-351. doi:10.1111/pbr.12059

Straka P, Nothnagel T (2002) A genetic map of Papaver somniferum $\mathrm{L}$. based on molecular and morphological markers. J Herbs Spices Med Plants 9:235-241. doi:10.1300/ J044v09n02_a

Tian CX, Liang XF, Yang M, Zheng HZ, Dou YQ, Cao L (2012) Isolation and characterization of novel genomic and ESTSSR markers in Coreoperca whiteheadi Boulenger and cross-species amplification. Int J Mol Sci 13:13203-13211. doi:10.3390/ijms131013203 
Turkish Soil Product Office (2009) Opium poppy report. Turkish Soil Production Office, Ankara

Varshney RK, Graner A, Sorrells ME (2005) Genic microsatellite markers in plants: features and applications. Trends Biotech 23:48-55. doi:10.1016/j.tibtech.2004.11.005

Winzer T, Gazda V, He Z, Kaminski F, Kern M, Larson TR, Li Y, Meade F, Teodor R, Vaistij FE, Walker C, Bowser TA, Graham IA (2012) A Papaver somniferum 10-gene cluster for synthesis of the anticancer alkaloid noscapine. Sci Exp 336:1704-1708. doi:10.1126/science.1220757

Zalapa JE, Cuevas H, Zhu H, Steffan S, Senalik D, Zeldin E, Mccown B, Harbut R, Simon P (2012) Using next-generation sequencing approaches to isolate simple sequence repeat
(SSR) loci in the plant sciences. Am J Bot 99:193-208. doi:10. 3732/ajb.1100394

Zhu H, Senalik D, McCown BH, Zeldin EL, Speers J, Hyman J, Bassil N, Hummer K, Simon PW, Zalapa JE (2012) Mining and validation of pyrosequenced simple sequence repeats (SSRs) from American cranberry (Vaccinium macrocarpon Ait.). Theor Appl Genet 124:87-96. doi:10. 1007/s00122-011-1689-2

Ziegler J, Facchini PJ, Geissler R, Schmidt J, Ammer C, Kramell R, Voigtländer S, Gesell A, Pienkny S, Brandt W (2009) Evolution of morphine biosynthesis in opium poppy. Phytochemistry 70:1696-1707. doi:10.1016/j.phytochem. 2009.07.006 